\title{
CORRECTION
}

W) Check for updates

Cite this: J. Mater. Chem. A, 2018, 6, 4878

DOI: $10.1039 / c 8 t a 90044 b$

www.rsc.org/MaterialsA

\section{Correction: Ammonia borane-polyethylene oxide composite materials for solid hydrogen storage}

A. S. Nathanson, ${ }^{a}$ A. R. Ploszajski, ${ }^{a}$ M. Billing, ${ }^{a}$ J. P. Cook, ${ }^{b}$ D. W. K. Jenkins, ${ }^{c}$ T. F. Headen, ${ }^{\text {b }}$ Z. Kurban, ${ }^{\text {b } A . ~ L o v e l l ~}{ }^{b}$ and S. M. Bennington ${ }^{b}$

Correction for 'Ammonia borane-polyethylene oxide composite materials for solid hydrogen storage' by A. S. Nathanson et al., J. Mater. Chem. A, 2015, 3, 3683-3691.

The authors regret a mistake in the abstract of the original article. In the sentence beginning "The new phase is characterised by hydrogen bonding between the hydridic hydrogen atoms..." the word 'hydridic' should be replaced by the word 'protic'. The correct sentence is "The new phase is characterised by hydrogen bonding between the protic hydrogen atoms bonded to the nitrogen atom in $\mathrm{AB}$ and the oxygen atom in PEO backbone."

The Royal Society of Chemistry apologises for these errors and any consequent inconvenience to authors and readers. 